\title{
An Investigation on the Mass Attenuation Coefficients of W-VC-C and W-VC-TiC-C Composites for Gamma Radioisotopes
}

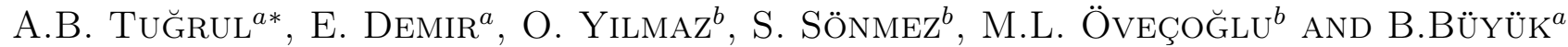 \\ ${ }^{a}$ Istanbul Technical University (ITU), Institute of Energy, Ayazaga Campus, 34469, Istanbul, Turkey \\ ${ }^{b}$ Istanbul Technical University (ITU), Particulate Materials Laboratories, \\ Dept. of Metallurgical and Materials Engineering, Ayazaga Campus, 34469, Sariyer, Istanbul, Turkey
}

\begin{abstract}
In this study, tungsten-vanadium carbide-graphite and tungsten-vanadium carbide-titanium carbide-graphite composites (W-VC-TiC-C) which can be used in high-tech equipment were investigated against different gamma radioisotopes. The composite materials were produced via mechanical alloying method in two groups; one of them includes $93 \%$ tungsten (W), $6 \%$ vanadium carbide (VC) and $1 \%$ graphite $(\mathrm{C})$ which was synthesized during three different alloying times $(6,12,24$ hours). Other group of the samples were composited as $91 \%$ tungsten, $6 \%$ vanadium carbide (VC), $2 \%$ titanium carbide $(\mathrm{TiC})$ and $1 \%$ graphite $(\mathrm{C})$ which has also three different alloying times $(6,12,24$ hours). Gamma transmission technique was used in the experiments to investigate the gamma attenuation properties of the composite materials. Linear and mass attenuation coefficients of the samples were determined in the experiments and theoretical mass attenuation coefficients were calculated using widely acknowledged XCOM computer code. The experimental mass attenuation coefficients and calculated theoretical results were compared and evaluated with each other. Results showed that gamma attenuation coefficients of the composite materials dependent on alloying time. It can be concluded that increasing the tungsten ratio causes higher linear attenuation coefficient which decreases with increasing gamma energies.
\end{abstract}

DOI: 10.12693/APhysPolA.129.724

PACS/topics: 25.20.Dc, 81.05.Mh

\section{Introduction}

Tungsten-based materials come into prominence for nuclear applications, particularly for fusion reactor applications. Tungsten-based composites are comparatively efficient gamma radiation shielding materials. They are preferred for radiation shielding applications because of having high melting points and good mechanical properties $[1,2]$.

Vanadium alloys have a lot of advantages especially as the shielding materials. They have been defined as promising candidate materials for first-wall blanket applications in the fusion systems because of their low activation properties, resistance and a high thermal stress factor to irradiation damage [3]. Vanadium-based alloys have been approved for many years as low activation materials, which thus have many advantageous properties [4]. Titanium carbide is an exceedingly hard, heat resisting ceramic material which has high melting point, superior chemical stability, low density, high hardness and thermal stability $[5,6]$.

European Union has released a directive in 2002 and made a second release in 2011 about the restriction of the use of some hazardous substances (RoHS), which include lead $(\mathrm{Pb})$, in electrical and electronic equipment. It has been also reported that there is no economic substitution

*corresponding author; e-mail: beril@itu.edu.tr material for lead in devices and systems intended for nuclear applications. It is known that lead is a commonly used radiation shielding material in nuclear applications and devices because of its good shielding properties and low cost. On the other hand lead is a toxic material. Thus there are studies looking for alternative materials which could be used in radiation shielding applications instead of the lead. Steels, tungsten alloys, concrete, aluminum alloys are some of these candidate material $[7,8]$.

In this study $\mathrm{W}-\mathrm{VC}-\mathrm{C}$ and $\mathrm{W}-\mathrm{VC}-\mathrm{TiC}-\mathrm{C}$ composites were investigated regarding shielding against gamma radiation sources. The measurements of mass attenuation and half of value thickness of materials were carried out. The possible uses of the tungsten-titanium vanadium composites instead of lead in radiation shielding applications were studied in view of RoHS Directive.

\section{Experimental procedures}

\subsection{Gamma sources}

For the production of the gamma radioisotopes Se75 and Sb-125 were irradiated in ITU TRIGA Mark II Training and Research Reactor at the Energy Institute of Istanbul Technical University. Se-75 and Sb-125 gamma radioisotopes were used as gamma sources, irradiation conditions of which are given in Table I. Se-75 has two major gamma peaks at $264 \mathrm{keV}$ and $401 \mathrm{keV}$ energy and a half life of 119 days [9]. Sb-125 has two major gamma peaks at 602 and $1692 \mathrm{keV}$. The half live of Sb-125 is 120.4 days [10]. 
TABLE I

Production conditions of Se-75 and Sb-125.

\begin{tabular}{c|c|c|c|c}
\hline \hline Radioisotopes & $\begin{array}{c}\text { Sample } \\
\text { Mass }[\mathrm{g}]\end{array}$ & $\begin{array}{c}\text { Irradiation } \\
\text { Power }[\mathrm{kW}]\end{array}$ & $\begin{array}{l}\text { Irradiation } \\
\text { Time }[\mathrm{min}]\end{array}$ & $\begin{array}{c}\text { Thermal Neutron } \\
\text { Flux }\left[\mathrm{cm}^{-2} \mathrm{~s}^{-1}\right]\end{array}$ \\
\hline Se-75 & 1 & 250 & 60 & $1.13 \times 10^{12}$ \\
Sb-125 & 1 & 250 & 60 & $1.13 \times 10^{12}$
\end{tabular}

\subsection{Gamma transmission technique}

Gama transmission technique which is shown in Fig. 1, is based on measurement of penetration of the gamma rays through materials [5]. The gamma rays which come from the source are detected by the detector with/without material.

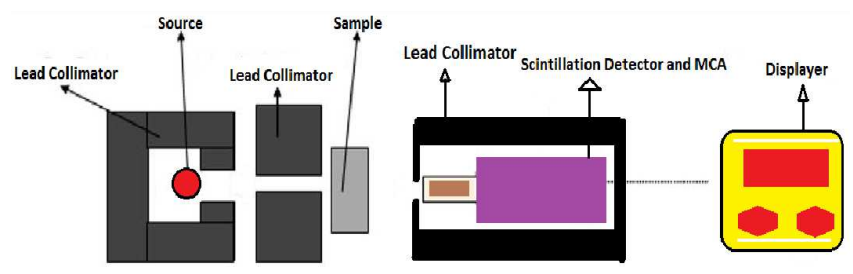

Fig. 1. The schematic view of the gamma transmission technique.

Canberra Model (802-2X2) NaI Scintillation detector, which has a $5.5 \mathrm{~cm}$ diameter and 14-pin tube, was used in the experiments. The detector was placed $2.5 \mathrm{~cm}$ from the source. Both the detector and the source were placed in the separate lead housings $(5 \mathrm{~cm}$ thick) which had a $7 \mathrm{~mm}$ hole on the same axis in front of each other and minimized the scattering effect. DigiBASE model PMT base with integrated bias supply, preamplifier and digital multichannel analyzer which was supplied with MAESTRO-32 MCA Emulation software, was used to count gamma radiation.

At first the background radiation and after that the initial gamma intensity without any material $\left(I_{0}\right)$ were measured. Then gamma intensities were measured for each materials at different thicknesses $(I)$. Net intensity counts were calculated by subtracting background. Each measurement was repeated minimum three times at accumulation time of $600 \mathrm{~s}$. Relative intensity $\left(I / I_{0}\right)$ values were calculated for the composite materials at different thicknesses. After that graphs which include relative intensity as function of material thickness were drawn.

\subsection{Materials}

Tungsten-vanadium carbide-graphite (W-VC-C) and tungsten-vanadium carbide-titanium carbide-graphite (W-VC-TiC-C) composites were used in the experiments. The composites were produced via mechanical alloying method at different alloying time values in the Particulate Materials Laboratories of Istanbul Technical University. Preliminary mechanical alloying experiments at times less than $6 \mathrm{~h}(1 \mathrm{~h}, 2 \mathrm{~h}, 4 \mathrm{~h})$ were conducted and the pertaining microstructures revealed lamellae formations in powders and convoluted powders, indicating intermediate stages of mechanical alloying [11]. At 6 hours, the microstructure consisted of equiaxed powders with no traces of lamellae lines, indicating the final stage of mechanical alloying. For this reason the starting mechanical alloying duration in this investigation was chosen as $6 \mathrm{~h}$. The composition and densities of the studied samples are given in Table II.

TABLE II

The contents of the studied W-VC-C and W-VC-TiC-C composites.

\begin{tabular}{c|c|c|c|c|c|c}
\hline $\begin{array}{c}\text { Material } \\
\text { code }\end{array}$ & $\begin{array}{c}\mathrm{W} \\
{[\% \text { Vol }]}\end{array}$ & $\begin{array}{c}\mathrm{VC} \\
{[\% \text { Vol }]}\end{array}$ & $\begin{array}{c}\mathrm{C} \\
{[\% \text { Vol }]}\end{array}$ & $\begin{array}{c}\text { TiC } \\
{[\% \text { Vol }]}\end{array}$ & $\begin{array}{c}\text { Time } \\
{[\mathrm{h}]}\end{array}$ & $\begin{array}{c}\text { Density } \\
{\left[\mathrm{g} / \mathrm{cm}^{3}\right]}\end{array}$ \\
\hline $6 \mathrm{~V}$ & 93 & 6 & 1 & - & 6 & 16.80 \\
$12 \mathrm{~V}$ & 93 & 6 & 1 & - & 12 & 16.50 \\
$24 \mathrm{~V}$ & 93 & 6 & 1 & - & 24 & 16.46 \\
$6 \mathrm{VT}$ & 91 & 6 & 1 & 2 & 6 & 16.21 \\
$12 \mathrm{VT}$ & 91 & 6 & 1 & 2 & 12 & 15.56 \\
$24 \mathrm{VT}$ & 91 & 6 & 1 & 2 & 24 & 15.44
\end{tabular}

\section{Results and discussion}

It is evident that cold work and stored energy increase with mechanical alloying times resulting in progressive increases in the amount of lattice defects. The increase of lattice defects causes a decrease of overall densities. In other words, the density decreases with mechanical alloying times. The material thickness vs relative intensity measurements of the W-VC-C and W-VC-TiC-C composites were carried out for Se-75 and Sb-125 gamma radioisotope sources. The results are given in Table III. The linear

TABLE III

Material thickness vs relative count values of the tungsten-vanadium-titanium composites.

\begin{tabular}{c|c|c|c|c|c}
\hline \hline \multirow{2}{*}{ Materials } & \multirow{3}{*}{ Thickness [cm] } & \multicolumn{2}{|c|}{ Se-75 } & \multicolumn{2}{|c}{ Sb-125 } \\
\cline { 3 - 6 } & & \multicolumn{4}{|c}{ Relative Count $\left(I / I_{0}\right)$} \\
\cline { 3 - 6 } & & 264 & 401 & 602 & 1692 \\
\cline { 3 - 6 } & & \multicolumn{4}{|c}{$[\mathrm{keV}]$} \\
\hline- & 0 & 1 & 1 & 1 \\
$6 \mathrm{~V}$ & 0.6003 & 0.3078 & 0.5917 & 0.3725 & 0.6207 \\
$12 \mathrm{~V}$ & 0.6506 & 0.2984 & 0.5924 & 0.3569 & 0.6022 \\
$24 \mathrm{~V}$ & 0.6077 & 0.2932 & 0.5993 & 0.3835 & 0.6729 \\
$6 \mathrm{VT}$ & 0.6285 & 0.3193 & 0.6075 & 0.3660 & 0.6454 \\
$12 \mathrm{VT}$ & 0.611 & 0.3306 & 0.6163 & 0.3973 & 0.6589 \\
$24 \mathrm{VT}$ & 0.6003 & 0.3110 & 0.5904 & 0.4085 & 0.6785
\end{tabular}

attenuation coefficient vs mechanical alloying time graphs were drawn for the tungsten-vanadiumcarbidegraphite (W-VC-C) and tungsten-vanadium carbidetitanium carbide-graphite (W-VC-TiC-C) composites against Se-75 and Sb-125 gamma sources. The graphs 
TABLE IV

The linear attenuation coefficients of the W-VC-C and $\mathrm{W}-\mathrm{VC}-\mathrm{TiC}-\mathrm{C}$ composite materials for Se-75 and Sb-125 sources.

\begin{tabular}{c|c|c|c|c}
\hline \hline \multirow{2}{*}{ Material } & \multicolumn{2}{|c|}{ Linear Attenuation Coefficients $\left[\mathrm{cm}^{-1}\right]$} \\
\cline { 2 - 5 } & \multicolumn{2}{|c}{ Se-75 } & \multicolumn{2}{c}{ Sb-125 } \\
\cline { 2 - 5 } & $264 \mathrm{keV}$ & $401 \mathrm{keV}$ & $602 \mathrm{keV}$ & $1692 \mathrm{keV}$ \\
\hline $6 \mathrm{~V}$ & 5.832 & 2.5975 & 1.6446 & 0.7941 \\
$12 \mathrm{~V}$ & 5.572 & 2.4125 & 1.5832 & 0.7795 \\
$24 \mathrm{~V}$ & 5.486 & 2.2894 & 1.5768 & 0.6517 \\
$6 \mathrm{VT}$ & 5.379 & 2.3475 & 1.5990 & 0.6967 \\
$12 \mathrm{VT}$ & 5.313 & 2.3203 & 1.5106 & 0.6826 \\
$24 \mathrm{VT}$ & 5.013 & 2.2625 & 1.4910 & 0.6459
\end{tabular}

were divided into two groups which can help us to evaluate the effects of alloying time and of the titanium additive on gamma shielding properties of the composites. Tables II-VI show the alloying time effect on the gamma attenuation properties of the samples for Se-75 and Sb125 gamma sources.

The calculated linear attenuation coefficients $(\mu)$ of the $\mathrm{W}-\mathrm{VC}-\mathrm{C}$ and $\mathrm{W}-\mathrm{VC}-\mathrm{TiC}-\mathrm{C}$ composites are shown in Table IV. For all composites, the experimental and theoretical mass attenuation coefficients are comparable with each other. The mass attenuation coefficients $\left(\mu_{m}\right)$, calculated using the linear attenuation coefficients, are given in Table V.

TABLE V

The mass attenuation coefficients of the W-VC-C and W-VC-TiC-C composites for Se-75 and Sb-125 sources.

\begin{tabular}{|c|c|c|c|c|c|c|c|c|}
\hline \multirow{4}{*}{ Material } & \multicolumn{8}{|c|}{ Mass Attenuation Coefficients $\left[\mathrm{cm}^{2} / \mathrm{g}\right]$} \\
\hline & \multicolumn{4}{|c|}{ Se-75 } & \multicolumn{4}{|c|}{$\mathrm{Sb}-125$} \\
\hline & \multicolumn{2}{|c|}{ Theoretical (XCOM) } & \multicolumn{2}{|c|}{ Experimental } & \multicolumn{2}{|c|}{ Theoretical (XCOM) } & \multicolumn{2}{|c|}{ Experimental } \\
\hline & $264 \mathrm{keV}$ & $401 \mathrm{keV}$ & $264 \mathrm{keV}$ & $401 \mathrm{keV}$ & $602 \mathrm{keV}$ & $1692 \mathrm{keV}$ & $602 \mathrm{keV}$ & $1692 \mathrm{keV}$ \\
\hline $6 \mathrm{~V}$ & 0.3693 & 0.171 & 0.3471 & 0.1546 & 0.1003 & 0.0462 & 0.0998 & 0.0482 \\
\hline $12 \mathrm{~V}$ & 0.3693 & 0.171 & 0.3367 & 0.1457 & 0.1003 & 0.0462 & 0.1002 & 0.0493 \\
\hline $24 \mathrm{~V}$ & 0.3693 & 0.171 & 0.3333 & 0.1309 & 0.1003 & 0.0462 & 0.1020 & 0.0421 \\
\hline $6 \mathrm{VT}$ & 0.3637 & 0.1693 & 0.3318 & 0.1448 & 0.0997 & 0.0462 & 0.1054 & 0.0459 \\
\hline $12 \mathrm{VT}$ & 0.3637 & 0.1693 & 0.3413 & 0.1490 & 0.0977 & 0.0462 & 0.1035 & 0.0467 \\
\hline $24 \mathrm{VT}$ & 0.3637 & 0.1693 & 0.3247 & 0.1465 & 0.0977 & 0.0462 & 0.0969 & 0.0420 \\
\hline
\end{tabular}

In addition, the half-value thicknesses were calculated using linear attenuation coefficients. The results are given in Table VI.

From Table VI it is seen that HVT values of the composite materials are very close to each other. Material denoted by symbol $6 \mathrm{~V}$ has slightly better gamma radiation properties than other materials.

\section{Conclusions}

Tungsten-vanadium carbide-graphite and tungstenvanadium carbide-titanium carbide-graphite composite materials were investigated as shielding materials against Se-75 and Sb-125 gamma radioisotope sources. The gamma attenuation properties were studied. The experimental mass attenuations were close to theoretical ones with the average differences under $10 \%$, which originate from the impurities and production methods. In addition HVT values for each sample were calculated and compared with each other and with values of some other materials. As expected, the densities of composites decrease progressively with mechanical alloying times.

$\mathrm{W}$-VC-C composites without $\mathrm{TiC}$ have better radiation shielding capabilities than the others for the studied gamma energies. The atomic number $Z$ of the absorber
TABLE VI

The half-value thicknesses of W-VC-C and W-VC-TiC-C composites for Se-75 and Sb-125 sources.

\begin{tabular}{c|c|c|c|c}
\hline \hline \multirow{2}{*}{ Material } & \multicolumn{3}{|c}{ Half Value Thickness [cm] } \\
\cline { 2 - 5 } & \multicolumn{2}{|c}{ Se-75 } & \multicolumn{2}{c}{ Sb-125 } \\
\cline { 2 - 5 } & $264 \mathrm{keV}$ & $401 \mathrm{keV}$ & $602 \mathrm{keV}$ & $1692 \mathrm{keV}$ \\
\hline $6 \mathrm{~V}$ & 0.119 & 0.266 & 0.4213 & 0.7941 \\
$12 \mathrm{~V}$ & 0.124 & 0.287 & 0.4377 & 0.7795 \\
$24 \mathrm{~V}$ & 0.126 & 0.302 & 0.4394 & 0.6517 \\
$6 \mathrm{VT}$ & 0.129 & 0.295 & 0.4333 & 0.6967 \\
$12 \mathrm{VT}$ & 0.130 & 0.298 & 0.4587 & 0.6826 \\
$24 \mathrm{VT}$ & 0.138 & 0.306 & 0.4647 & 0.6459
\end{tabular}

is very important. Therefore, it can be said that radiation capability of $\mathrm{W}-\mathrm{VC}-\mathrm{C}$ is more important than that of W-VC-TiC-C, because the titanium, used as the additive element in the composite, is a lighter metal than the $\mathrm{W}$ and . In addition, alloying time has a negative effect on the gamma shielding properties for the all studied W-VC-C and W-VC-TiC-C composites. In conclusion mechanically alloyed W-VC-C and W-VC-TiC-C composites were investigated against the Se-75 and Sb125 gamma sources, produced in ITU TRIGA Mark-II reactor. 


\section{References}

[1] N.P. Taylor, R. Pampin, Fusion Eng. Des. 81, 1333 (2006).

[2] A. Cambe, E. Gauthier, J.M. Layet, S. Bentivegna, Fusion Eng. Des. 56-57, 331 (2001).

[3] H.M. Chung, B.A. Loomis, D.L. Smith, J. Nucl. Mater. 239, 139 (1996).

[4] D.L. Smith, H.M. Chung, B.A. Loomis, H. Matsui, S. Votinov, V.W. Witzenburg, Fusion Eng. Des. 29, 399 (1995).

[5] B. Buyuk, A.B. Tugrul, Radiat. Phys. Chem. 97, 354 (2014).

[6] M.S. Kovalchenko, Int. J. Refractory Met. Hard Mater. 39, 32 (2013).
[7] DIRECTIVE 2011/65/EU on the restriction of the use of certain hazardous substances in electrical and electronic equipment (recast) (L 174/88 Official Journal of the European Union 1.7), (2011).

[8] R. Groß, D. Bunke, C.-O. Gensch, S. Zangl, A. Manhart, Study on Hazardous Substances in Electrical and Electronic Equipment, Not Regulated by the RoHS Directive, (2008)

[9] http://ehs.unl.edu/sop/SP_SOP_Se-75.pdf, (2015).

[10] http://www.nucleide.org/DDEP_WG/Nuclides/ Sb-125_tables.pdf, (2015).

[11] C. Suryanarayana, Nasser Al-Aqeeli, Prog. Mater. Sci. 58, 383 (2013). 